\title{
A FRAMEWORK FOR RELIABLE THREE-DIMENSIONAL UNDERGROUND UTILITY MAPPING FOR URBAN PLANNING
}

\author{
R. van Son ${ }^{1}$, Jaw S.W. ${ }^{1,2,3}$, Yan J. ${ }^{1}$, V. Khoo H.S. ${ }^{4}$, R. Loo W.K. ${ }^{4}$, S. Teo S.N. ${ }^{4}$, G. Schrotter ${ }^{5}$ \\ ${ }^{1}$ Future Cities Laboratory, Singapore-ETH Centre, ETH Zürich- (vanson, jaw, jingya.yan)@arch.ethz.ch \\ ${ }^{2}$ Geoscience \& Digital Eaeth Centre (INSTeG), Research Institute for Sustainable Environment, Universiti Teknologi Malaysia, \\ Malaysia-swjaw@utm.my \\ ${ }^{3}$ Department of Geoinformation, Faculty of Geoinformation \& Real Estate, Universiti Teknologi Malaysia, Malaysia \\ ${ }^{4}$ Land Surveying Division, Singapore Land Authority - (victor_khoo, richard_loo, sandy_teo)@sla.gov.sg \\ ${ }^{5}$ Geomatik - Vermessung, Stadt Zürich - (gerhard.schrotter@zuerich.ch)
}

Commission VI, WG VI/4

KEY WORDS: Underground Utility Mapping, 3D Mapping, Urban Planning, Mapping Standards and Guidelines

\begin{abstract}
:
To optimise the use of limited available land, land-scarce cities such as Singapore are increasingly looking towards the underground in search of more space. A good understanding of what already exists underground is essential for the planning of underground spaces. In particular, utility services make up a significant part of what exists underground. To meet planning needs, the Singapore government has initiated efforts towards bringing records of existing utility networks together in a single database and share its contents to support planning, design, and construction of underground developments. However, these records can not be relied on to support these critical processes: They are not guaranteed to represent today's state of the underground, are not accurate or of unknown accuracy, are inconsistently modelled, and may indicate as-design information instead of as-built information. This lack of reliability leads to an increase in cost and a loss in efficiency caused by the need to repeatedly survey to locate existing utility services on-site, and can have potentially disastrous outcomes when an excavation would damage existing services. Technological advances in utility surveying and mapping devices such as Ground Penetrating Radar (GPR) and gyroscopic pipeline mapping devices offer the potential of accurately mapping utilities in three dimensions (3D) at a large scale and high speed. However, a better understanding of the benefits and limitations of these technologies in a practical context is needed, as well as their suitability for mapping to support applications such as urban planning and land administration. The Digital Underground project is a collaboration between Singapore-ETH Centre, Singapore Land Authority and the City of Zürich that aims to develop a roadmap towards a reliable 3D utility map of Singapore. To enable the development of utility mapping standards and guidelines, the 3D mapping workflow for underground utilities is studied extensively based on market research, literature study, and case studies. This work presents the beginnings of a framework for 3D mapping of underground utilities as one of the initial results of the Digital Underground project as it is in progress. From these experiences, it can be concluded that, together with existing data, data captured using various surveying methods can indeed contribute to the establishment and maintenance of a consolidated and reliable utility map. To this end, a multi-sensor, multi-data 3D mapping workflow is proposed to integrate data captured using different surveying techniques during different moments in the development lifecycle of utilities. Based on this framework, this work also identifies areas for improvement and critical gaps to be bridged that will ultimately form part of the roadmap.
\end{abstract}

\section{INTRODUCTION}

\subsection{The need for a reliable 3D map of underground utilities}

The city-state of Singapore has a strong need for a reliable 3D map of underground utilities for the purpose of urban planning. A number of developments are driving this need. First of all, being a land-scarce city, Singapore faces the challenge of optimising the use of available space for homes, office, and greenery. To use space efficiently, the Singaporean government aims for solutions utilizing the subterranean space. It will be launching its Underground Master Plan in 2019. To develop the Underground Master Plan and to check if proposed future developments fit that plan, a comprehensive view of what lies underground is needed. To this end, it is necessary to "take stock of what is underground, including pipes and power grids" $(\mathrm{Ng}$, 2018).

Secondly, legislative changes to facilitate future planning and development of underground space have been introduced in Singapore in 2015 (Ministry of Law, 2015). These changes clarify underground ownership to a greater level of detail than before, and will allow for the acquisition of specific strata of land. Land administration and development agencies therefore need to have an accurate understanding of what exists underground and who it belongs to.

Lastly, to support efficient construction and maintenance work of underground services and assets, prevent damage to existing infrastructure, and increase safety of workers on-site, a detailed and complete understanding of what exists underground is required. Not being able to rely on information of the underground usually results in the digging of costly and delaying trial pits.

To establish a map of the underground including utility services, government agencies (e.g. utility owners, land developers, and land owners) have already started sharing their data using Singapore Land Authority's GeoSpace platform. However, a number of issues prevent this data from being reliable for the purposes of urban planning, land administration, and on-site work. First, the data is often $2 \mathrm{D}$ or $2.5 \mathrm{D}$ (i.e. with depths measured at accessible manhole locations only) instead of 3D. Second, it is uncertain whether this data accurately represents the 
existing situation due to 1) inaccurate measurements, 2) possibly representing the as-designed instead of the eventual as-built state, and 3) ambiguous depth or elevation values (e.g. with reference to an absolute height datum, or to a surface with unknown elevation). Third, much of the attribute information required to support specific applications is not available or represented in a generic manner.

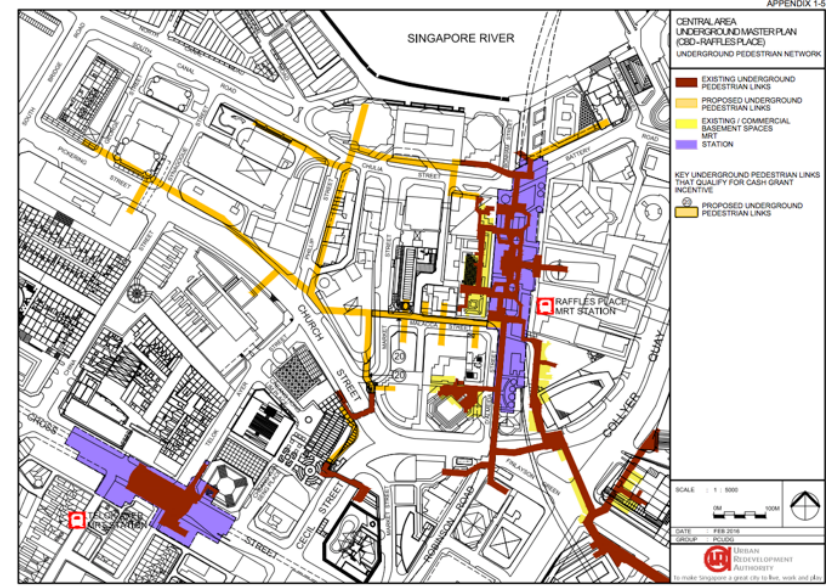

Figure 1. Drawing of Underground Master Plan for Singapore's Central Area, indicating existing and proposed underground pedestrian links.

\subsection{Advances in mapping technology}

As noted by Frith et al. (2017), the processes of collecting new data about subsurface features may be initiated not just by the installation of new infrastructure or new needs that necessitate the capture of new data of existing infrastructure. Improvements to data capture techniques that could result in higher quality or more refined data are another driver of developments towards newly acquiring utility data.

Typically, the mapping of underground utilities is a laborious effort and, in the case of mapping buried utilities, often highly dependent on the interpretation and experience of the user. Recent advances in capturing technology for underground utilities suggest that it will be possible to capture reliable data more efficiently. For example, mobile ground penetrating radar arrays such as IDS' Pegasus Stream EM (IDS, 2018) and the Impulse Radar's Raptor system (Impulse Radar, 2018) can be used to capture dense, large volumes of data for a large area. Supporting tooling such as the inclusion of existing GIS data for mapping (Tabarro et al., 2017) and augmented reality technology may be used to overlay existing map data as well as newly captured information (Côté and Girard-Vallée, 2015). For secondary data capture, software tools that support the user by automating large parts of the mapping process may help increase efficiency and accuracy of produced results.

This work will describe activities conducted within the context of the Digital Underground project, a collaboration between Singapore-ETH Centre and Singapore Land Authority. First, an overview of the project and its results so far is presented. After that, the foundations of a framework for 3D mapping underground utilities are presented. This is followed by an overview of case studies that will be conducted in the near future. After the concluding remarks, the project's next steps towards a complete and comprehensive framework for 3D mapping are described.

\section{THE DIGITAL UNDERGROUND PROJECT: TOWARDS A RELIABLE 3D MAP OF UTILITIES}

Digital Underground is a research-to-application project that has started in the beginning of 2018 that aims to support the Singapore Land Authority to achieve the objective of a reliable 3D map of utilities underground (Jaw et al., 2018). The project aims to deliver a roadmap, outlining a detailed description of the desired future, and the necessary milestones and activities to realise that goal. The other objectives of the project are 1) to develop a data model framework for surveying, data management, and application of underground utility data and 2) to establish best practices for mapping underground utilities.

\subsection{Roadmap}

The roadmap is a strategic plan that describes the steps Singaporean government agencies need to take to achieve a reliable $3 \mathrm{D}$ map of utilities underground. Its objective is to clearly define tasks, priorities, and milestones for action in the near, medium and long term. To gather input and establish support from stakeholders, the roadmap is developed in a series of workshops with representatives of various Singaporean government agencies, as well as experts from industry and academia.

Preliminary results from the first workshops indicate that the roadmap should not only guide the way towards a reliable 3D map of utilities underground, but rather to a so-called utility mapping ecosystem that enables collaboration between government agencies and industry service providers, reliable data capture, a platform for data management and storage, a legal framework for sharing and using data, and the capability to adapt to future needs and developments.

The roadmap development activities are supplemented by other activities aimed at involving stakeholders and raising awareness. For example, the project team has guided a delegation of professionals from government agencies on a study trip to Hong Kong. Also, a showcase using augmented reality technology was developed to paint a picture of a possible future applications enabled by a reliable $3 \mathrm{~d}$ map of utilities underground (Figure 2).

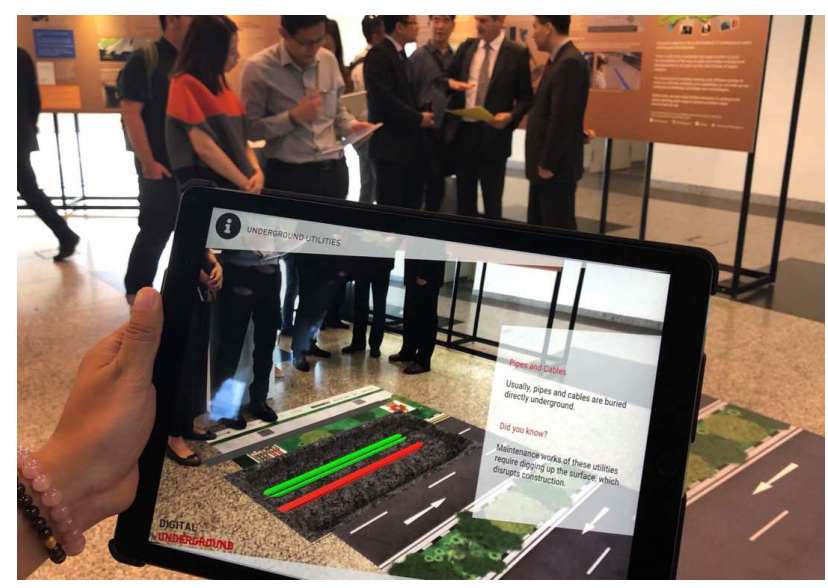

Figure 2. Digital Underground exhibition showcase, painting a picture of the desired future.

\subsection{Data model framework}

A data model for underground utilities is required for the following reasons: 1) to represent and store utility map data, 2) 
to ensure selected applications such as urban planning and land administration can be supported with the right data, and 3) to drive output requirements for data capture methods and technology.

Currently, developments are underway for a framework to describe and organise the data flow from capture to usage at a high level. It aims to resolve issues about communication between different organisations, data integration, and data sharing for a 3D map of underground utility services. To evaluate the framework, a vertically integrated use case for a data model for land administration purposes will be developed and demonstrated in collaboration with Singapore Land Authority.

\subsection{Best practices for 3D mapping of underground utilities}

The third objective of the Digital Underground project is to develop and strengthen government agencies' understanding of methods and technologies for 3D mapping. This should enable them to engage with industry technology and service providers and specify guidelines for data capture, quality and submission. The outline for this work is as follows. First, a framework for 3D utility mapping will be developed based on market research. This framework contains a comprehensive overview of available and feasible data capture methods and technologies - from primary to secondary data capture, describing input and output and suitable use cases. Second, based on assessment of on-site practices, soil conditions, and specific characteristics of utility services in Singapore (e.g. typical buried depth, size, material) these methods and technologies are evaluated based on a literature study on past research. Finally, a selection of data capture methods is evaluated hands-on in a case study approach.

Combined, the results of these studies will give insight into 1) the expected accuracy and reliability of 3D data produced, 2) the value and applicability of these data capture methods for selected urban planning applications in the Singaporean context, and 3) the practical feasibility (i.e. cost, availability, ease of use, ease of integration in existing practices) of these methods and technologies for 3D mapping.

In the following sections, results from work in progress on the best practices are presented. These include a part of the 3D mapping framework, focusing on primary data capture, and an outline of the to be conducted case studies.

\section{3D MAPPING FRAMEWORK}

The 3D mapping framework offers a comprehensive overview of off the shelf, commercially available methods and technologies for 3D mapping. The purpose of the framework is to give government agencies that commission the data capture of underground utility infrastructures a realistic, complete, and high-level understanding of the available technologies, the conditions under which they may be used, and their benefits and limitations. The framework covers the process from surveying (primary data capture) to mapping (secondary data capture) and incorporates both hardware and software technology.

\subsection{Methods and technologies for primary data capture}

In this section, an overview of methods and technologies for the capture of primary data on underground utilities is presented.

\subsubsection{Traditional surveying}

Traditional surveying techniques using a total station or GNSS Real Time Kinematic (RTK) are recommended by the Singapore
Land Authority for the survey of newly built utility services (Singapore Land Authority, 2017). When using a total station, control points are measured. Utility features are then observed by multiple radial sideshots from primary project control points.

Real-time Kinematic surveying is a GNSS carrier phase surveying technique that allows the user to rapidly and accurately measure baselines while moving from one point to the next, stopping only briefly at the unknown points, or in dynamic motion such as in a survey boat or aircraft. By taking reference to Singapore Satellite Positioning Reference Network (SiReNT) stations, a remote, or rover, receiver traverses between the unknown points to be positioned. The data is collected and processed real-time to obtain accurate positions to the centimeter level.

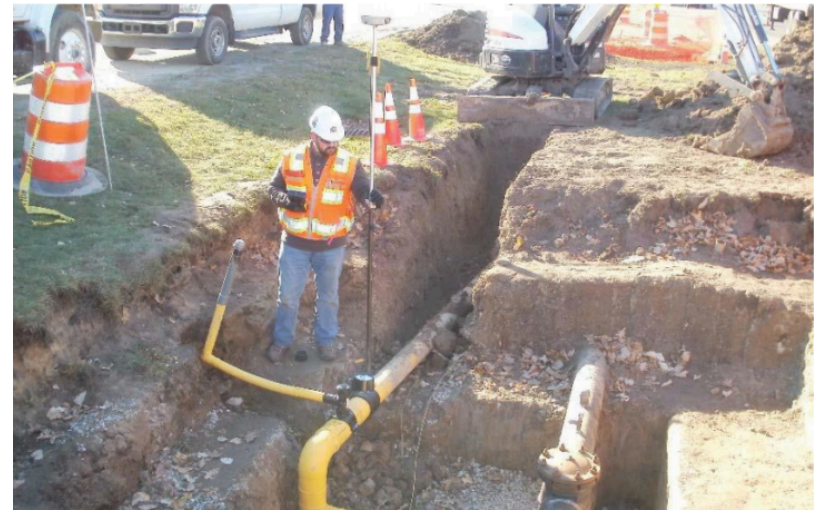

Figure 3. Surveyor recording GNSS observation on a gas main in Michigan, United States.

\subsubsection{Point cloud-based methods}

Point clouds, acquired using either laser scanners or photogrammetry techniques, are typically used for $3 \mathrm{D}$ data acquisition of above-ground, visible features. For the relatively short time when utility services are visible during (open pit) construction or maintenance, these methods may be applied to underground utilities as well.

Point clouds are useful as a visualisation tool by themselves, but are often used to reconstruct detailed geometry and visual information in the secondary data capture process. An example project in which point clouds are used to reconstruct underground utility services and assets is the work on an underground infrastructure mapping platform by City Digital (UI Labs, 2016).

\subsubsection{Ground Penetrating Radar}

Ground penetrating radar (GPR) is one of the most commonly used technologies for the detection and mapping of utilities buried underground (Lai et al., 2018). The GPR antenna transmits electromagnetic signals into the ground and records the signals that are reflected on the ground surface when it encounters buried objects. Off the shelf ground penetrating radar systems are typically incorporated into a small trolley that can be pushed over the target area.

So-called B-Scans (two-dimensional radargrams) can be generated from a series of signal traces along a trajectory. BScans are then interpreted by an operator and the possible locations of utility services marked. By pushing the trolley over the target area in a grid pattern, multiple B-Scans can be combined into a three-dimensional C-Scan. 


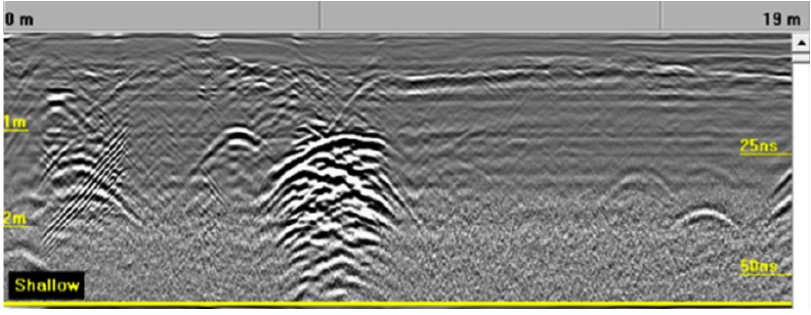

Figure 4. Example of a B-Scan radargram, with hyperbola indicating possible utility services

\subsubsection{D Ground Penetrating Radar}

Although it is possible to generate three-dimensional radargrams using conventional GPR, this approach is labour-intensive and will typically result in $3 \mathrm{D}$ radargrams with a relatively low resolution. Over the past years, manufacturers such as Ingegneria Dei Sistemi (IDS) have developed multichannel 3D GPR array systems (Novo et al., 2013). These array systems consist of a large number of closely-spaced antennas, enabling them to produce high-resolution 3D radargrams in a relatively small amount of time.

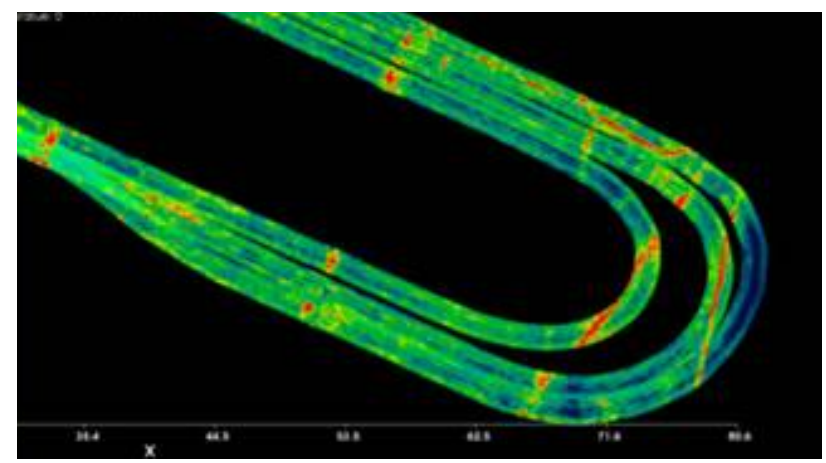

Figure 5. Example of a C-Scan slice for a particular depth, with red colours indicating possible utility services underneath a road.

Although mapping arrays can be incorporated in manually pushed trolley based systems, recent 3D GPR arrays such as the IDS Stream EM (IDS, 2018) and the Impulse Radar Raptor (Impulse Radar, 2018) can be towed by regular road-based vehicles. This offers the potential of capturing large volumes of data in a relatively small amount of time, while at the same time minimizing traffic disruptions.

\subsubsection{Gyroscopic mapping}

For new utility services that have been constructed using trenchless technologies such as Horizontal Directional Drilling (HDD) or pipe jacking, the open pit situation required for traditional surveying is never available. To accurately map the trajectory of a newly built, empty pipe, gyroscopic mapping technology may be employed.

The Reduct DuctRunner, claimed to be the world's first small diameter pipeline mapping technology based on inertial sensor technology, contains an Orientation Measurement Unit (OMU) that logs the changes in the $\mathrm{X}$-direction (distance), $\mathrm{Y}$-direction (heading), Z-direction (pitch) and Roll position between an entry point and exit point (Reduct, 2017). From its entry point, it is pulled through the centre a pipe, recording its trajectory. Combined with an accurate georeferenced measurement of the entry and exit point and after the recommended amount of at least 4 runs though a pipe, an accuracy of $15 \mathrm{~cm}$ in $\mathrm{XYZ}$ over a distance of 500 meter can be expected. The drawback of this method is that it can only be used when the pipe is still clear of any contents.

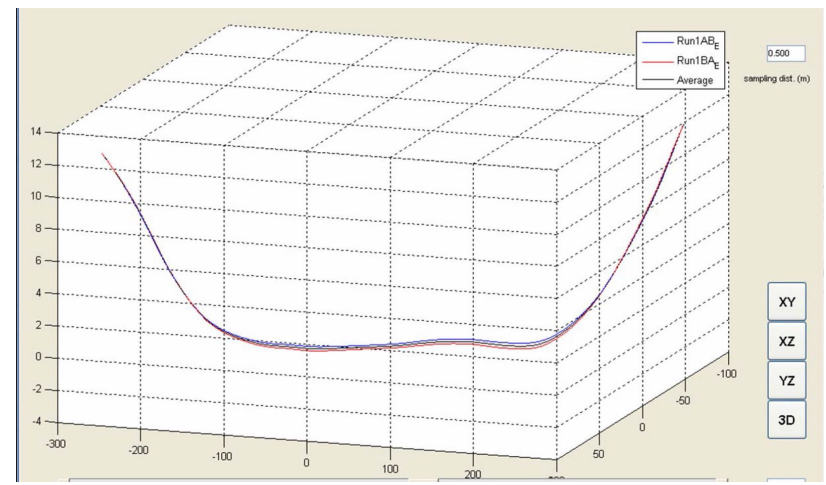

Figure 6. 3D view of a Reduct scanned trajectory.

\subsubsection{RFID}

Passive Radio Frequency Identification (RFID) markers may be attached to the top of a pipe during installation. Using a dedicated detection instrument such as the Eliot RFID Detector (Eliot, 2018), the horizontal location and depth of the marker and consequently that of the attached pipe, can be established if the pipe is buried no deeper than 1.5 meters. Aside from a single demonstration site, RFID markers for mapping have not been installed on any services yet in Singapore.

\subsubsection{Overview}

An overview of all methods for primary data collection, their typical use case situation for mapping utilities, and output primary data are desribed in Table 1 .

\begin{tabular}{|l|c|c|}
\hline Method & Use case & Primary data \\
\hline Traditional surveying & Open pit & Sparse points \\
\hline $\begin{array}{l}\text { Laser \& } \\
\text { photogrammetry }\end{array}$ & Open pit & $\begin{array}{c}\text { Dense point cloud, } \\
\text { color }\end{array}$ \\
\hline GPR & Buried & B-Scan radargram \\
\hline 3D GPR & Buried & C-Scan radargram \\
\hline Gyroscopic mapping & $\begin{array}{c}\text { Buried, newly } \\
\text { built }\end{array}$ & $\begin{array}{c}\text { Dense points along } \\
\text { centre line of pipe }\end{array}$ \\
\hline RFID & Buried & $\begin{array}{c}\text { Sparse points with } \\
\text { offset from service }\end{array}$ \\
\hline
\end{tabular}

Table 1 . Overview of 3D utility mapping methods

\section{CASE STUDIES FOR DATA CAPTURE}

To develop a good understanding of the practical feasibility of available methods and technologies for data capture, they should be evaluated in a Singaporean context. To this end, a number of case studies have been planned that focus on mapping existing, buried services. Besides evaluating the available methods and technologies, the secondary objective of the case studies is to showcase these methods to increase public awareness of the possibilities of utility mapping technology among government and industry service providers in Singapore.

\subsection{Ground penetrating radar}

The first case study will evaluate a trolley-based, multi-frequency GPR system. The objectives of this case study are to 1) establish and experience a baseline for GPR data capture hands-on, and 2) evaluate the performance of GPR in various environments and conditions in Singapore. To this end, a number of locations will 
be selected based on knowledge of the location existing services underground as well as soil conditions.

\subsection{Mobile 3D ground penetrating radar}

The second case study will evaluate the use of a state-of-the-art $3 \mathrm{D}$ mobile mapping solution for rapid, large volume underground data capture. The objectives of this case study are to 1) compare the workflow and results to conventional GPR, and 2) to develop an understanding of the practical and legal issues of operating a mobile 3D GPR on the public roads of Singapore. For case study locations, $1 \times 1 \mathrm{~km}$ areas within an old residential estate, a new residential estate, and an industrial estate have been selected.

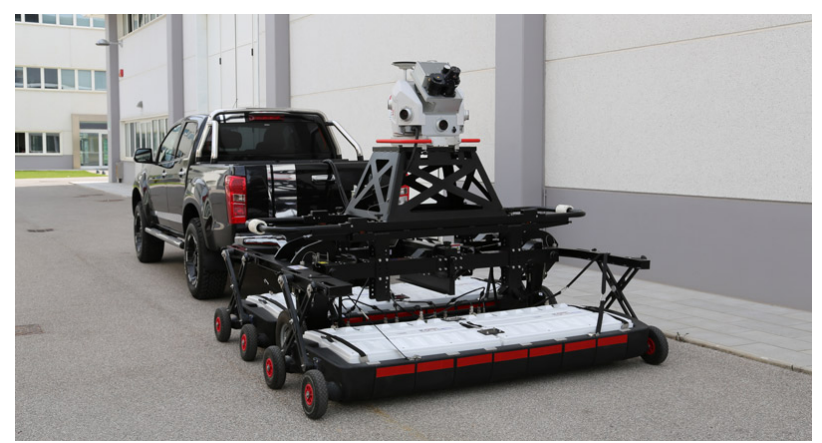

Figure 7. The IDS Pegasus:Stream combined above-ground and underground data capture platform is considered for a case study on mobile 3D GPR.

\subsection{Gyroscopic mapping}

The third case study will evaluate the use of the Reduct DuctRunner gyroscopic mapper. The objectives of the case study are to 1) assess the accuracy of the gyroscopic mapping method, and 2) to develop an understanding of on-site use of the method and the consequences for construction and surveying practices. In collaboration with industry service providers, a site will be selected in which both traditional surveying before covering up and gyroscopic mapping after covering up are conducted.

\section{CONCLUSIONS}

In this work, an overview of the Digital Underground project's efforts towards a reliable 3D map of utilities underground in Singapore are described.

In Singapore, the development of an Underground Master Plan and legislative changes impacting underground land administration necessitate the need for accurate, reliable 3D information of what exists underground, including utility services and assets. Although data about the location of utilities is shared between government agencies, this data can't be considered reliable for the intended applications.

The advent of new and accurate methods and technologies for underground utility data capture necessitate investigations into the accuracy and reliability of the data captured, and the practical feasibility of such technologies in the Singaporean context. To establish best practices for 3D utility mapping, the Digital Underground project has initiatied the development of a framework for 3D mapping of utilities. At the current stage, it consists of an overview of methods for primary data capture. Future case studies have been outlined and will be conducted in the next stage of the project.
Based on the overview of methods and technologies for primary data capture, it can be concluded that a one-size-fits-all data capture solution does not exist. The best moment for doing accurate measurements is arguably when a utility service has just been built. However, traditional surveying techniques may not always suffice, for example in the case of pipes built using trenchless technology. Point-cloud based methods, on the other hadn, offer the possibility to map more than just the location of a service (e.g. visual appearance, complex geometry).

For mapping existing, buried services, conventional ground penetrating radar has its limitations, depending heavily on the experience and interpretation of the operator. While being costly, 3D GPR arrays appear much more suited for the specific application of mapping.

This project will continue the development of best practices for $3 \mathrm{D}$ mapping. Case studies will serve as a means to further develop and validate the 3D mapping framework. The end result will be a multi-sensor, multi-data 3D mapping workflow that is capable of integrating various data sources captured using different data capture methods on different moments in the development lifecycle of utilities.

\section{NEXT STEPS FOR DIGITAL UNDERGROUND}

The Digital Underground aims to continue until the end of the first quarter of 2019. Roadmap development will continue in the form of expert workshops, in which experts from industry and academia will highlight the most significant opportunities and obstacles on the path towards a utility mapping ecosystem in Singapore. Also, development of the data model framework will continue with the identification of detailed data model needs for urban planning applications.

The development of the 3D mapping framework will occur along two directions: 1) Refinement of the framework, assessing feasibility of data capture methods based on data model needs and case studies and 2) extension of the framework, charting out methods for secondary data capture, i.e. software for postprocessing, data analysis, and data modeling.

Eventually, the vertically integrated use case for a data model for land administration purposes will serve as a means to demonstrate and evaluate a complete workflow from data capture to data modeling, to storage and usage of the data for a specific application.

\section{ACKNOWLEDGEMENTS}

This publication has been realized as part of the Digital Underground: 3D Mapping of Utility Networks project at the Future Cities Laboratory, established by ETH-Zurich and the Singapore National Research Foundation (NRF), and operating under the auspices of the Singapore-ETH Centre. The project is funded by the UNDERGROUND-RELATED STUDIES AND PROJECTS FUND (USPF) of the Ministry of National Development of Singapore and is sponsored by Singapore Land Authority.

\section{REFERENCES}

Côté, S. and Girard-Vallée, A., 2015. Accurate OnSite Georeferenced Subsurface Utility Model Visualisation. In: Proceedings of the Second International Conference on Augmented and Virtual Reality, Vol. 9254,

pp. 63-70. 
Eliot, 2018. Eliot RFID Detector. Ryb https://www.rybbtp.fr/portfolio-item/eliot-detector/ (15 July 2018).

Frith, N., Catchpole, S., Home, R., Watson, C., and Kessler, H., 2017. A Unified Data Framework for Mapping Underground. Project Iceberg https://futurecities.catapult.org.uk/wpcontent/uploads/2017/12/Project-Iceberg-Work-Package-2Report.pdf (15 July 2018).

IDS GeoRadar, 2018. Stream EM: Ground Penetrating Radar for Utility Location and Mapping. IDS Georadar https://idsgeoradar.com/products/ground-penetratingradar/stream-em (15 July 2018).

Impulse Radar, 2018. Raptor: High Speed Separable Shielded GPR Antenna Solution. Impulse Radar http://www.impulseradar.se/products/raptor/ (15 July 2018).

Lai, W. W.-L., Drobert, X. and Annan, P., 2018. A review of ground penetrating radar application in civil engineering: a 30year journey from locating and testing to imaging and diagnosis. NDT \& E International 96, pp. 58-78.

Jaw, S. W., Son, R. V., Soon, V. K. H., Schrotter, G., Kiah, R. L. W., Ni, S. T. S. and Yan, J., 2018. The Need for a Reliable Map of Utility Networks for Planning Underground Spaces. Rapperswil, Switzerland.

Ministry of Law, 2015. Legislative changes to facilitate future planning and development of underground space. Ministry of Law https://www.mlaw.gov.sg/content/minlaw/en/news/pressreleases/legislative-changes-planning-developmentunderground-space.html (15 July 2018).

Ng, J.S., 2018. Masterplan of Singapore's underground spaces ready by 2019 . Straits Times https://www.straitstimes.com/politics/masterplan-of-sporesunderground-spaces-ready-by-next-year (15 July 2018).

Novo, A., Manacorda, G., and Simi, A., 2013. Multichannel 3D GPR array systems: Recent results in engineering and archaeology. 26th Symposium on the Application of Geophysics to Engineering and Environmental Problems 2013, pp. 433441 .

Singapore Land Authority, 2017. Standard and Specifications for Utility Survey in Singapore. Singapore Land Authority https://www.sla.gov.sg/Press-Room/Circulars/Land-Survey (15 July 2018).

Tabarro, G.M., Pouliot, J., Fortier, R., and Losier, L.-M., 2017. A WebGIS to support GPR 3D Data Acquisition: A First Step for the Integration of Underground Utility Networks in 3D City Models. In: International Archives of the Photogrammetry, Remote Sensing and Spatial Information Sciences, Vol. XLII4/W7. pp. 43-48.

UI Labs, 2016. City Digital Announces Development of Technology to Create New Underground Infrastructure Mapping Platform. UI Labs https://www.uilabs.org/press/citydigital-announces-development-of-technology-to-create-newunderground-infrastructure-mapping-platform/ (15 July 2018). 